\title{
The ethics of "primo non nocere", professional responsibility and shared decision making in high-stakes neurosurgery
}

\author{
Christian Munthe
}

Received: 19 February 2015 / Accepted: 23 February 2015/Published online: 7 March 2015

(C) Springer-Verlag Wien 2015

\section{Dear editor,}

Having been alerted to a debate on high-stakes neurosurgery policy ensuing in Acta Neurochirurgica because of an article by Brennum and colleagues [1], I have been kindly invited to submit a comment from the point of view of a medical ethics researcher. I will describe some underlying constituents of the apparent disagreement between Brennum's team and of Duffau, who criticised their original suggestion in an editorial [2], taking into acount a recent response by Brennum's team [3]. I will complicate the issue on a theoretical level, keeping apart a number of distinct ethics considerations. I will not comment on medical facts, but proceed on the assumtion that there is an actual dilemma faced in the cases discussed. I will also limit my discussion to the type of case seemingly illustrated by the surgical procedure discussed, which may be called high-stakes surgery. This is when a patient is in dire circumstances, facing a fatal outcome, where more expansive surgery may delay this outcome (further), but at the expense of increased risk of major functional damage (in the case at hand, as I understand, e.g. loss of eyesight and/or limb mobility).

It is a common situation in medicine, and a classic ethical issue how to respond to it, to have procedures providing a chance of substantial benefit, but also imposing significant risk. This relates to a number of underlying ethical queries, and it is important to be clear about exactly which one of these is being debated. In addition, the issue may harbour more or

C. Munthe $(\varangle)$

Department of Philosophy, Linguistics and Theory of Science, University of Gothenburg, Box 200, 40530 Gothenburg, Sweden e-mail: christian.munthe@gu.se less complexity with regard to what values are at stake. Sometimes, the benefits and risks of a procedure can be spelled out in similar terms - say, length of life - and in those cases, the decision on whether or not to opt for a particular procedure may look simple: it is all about choosing a design with the most favourable probability ratio. In the case at hand, however, the situation is less simple, as several distinct values are at stake, and it is unclear how they should be properly balanced.

One issue, then, is about how to ethically assess the values at stake in high-stakes neurosurgery. The discussants seem to agree on the value of the length of life. Less clear, however, is how they value functional loss. A functional impairment can be assessed from at least three classic value perspectives: two subjective and one objective [4]. The latter means that the impairment is valued on the basis of an objective ideal of a human being. Its value will always be the same, always implying a loss of the same gravity. On the subjective accounts, the value instead depends on how the affected individual subjectively relates to the impairment, in terms of well-being or in terms of preference. Of these, the latter means that even a very gruesome (e.g. in terms of pain) condition need not be so bad, given that the affected person accepts it. Brennum's team may be slightly more inclined to take this view rather than assessing impairment in terms of loss of subjective well-being, although it may also be that they weigh this value differently from Duffau when balancing against the chance of extending life. Duffau, on his part, displays traces of a more objective view of the value of functional loss, subject to the same qualificaltion as before. Such differences may make the parties value the prospect of extended life differently, despite initial appearance, as both seem to agree that the value of life assumes a life of some quality. 
Another basic ethical issue is how to assess (more or less) uncertain benefits and burdens of procedures in terms of a risk assessment. It is not given how probabilities of outcomes are to be aggregated with value assessments into a final judgement of whether or not certain options should be pursued. In fact, this issue has proved increasingly difficult to analyse also in basic ethical theory [5], giving rise to well-known conundrums in medical research ethics, e.g. on how to decide stopping criteria in clinical trials [6]. In the case of high-stakes neurosurgery, the issue that may give rise to differences of opinion is about how outcomes viewed as very grave are to be assessed when merely possibly following an otherwise benign action. One interpretation of the conflict is that Duffau views any slight increase of a risk of major functional loss as a "defeater" that silences all other reasons, at least unless the prospect of a "cure" is in sight. Brennum's team, in contrast, seems to have a less principled outlook, allowing such risks to be worth taking depending on circumstances.

These basic issues can be related to two distinct, but linked, medical ethical issues. One of these is about professional responsibility: what qualities must a procedure possess in order for a professional to responsibly offer it to patients? This question is answered when medical specialities decide on diagnostic categories, indications, and treatment guidelines, and such answers express a "menu" of allegedly acceptable professional practices. Both of the formerly mentioned issues factor into what reasons may be brought to the fore in designing such an answer. But there are also additional aspects to consider, such as how the answer may affect the public trust of medicine and health care institutions, or whether or not patient expectations may imply false assumptions about the effectiveness and safety of offered procedures. My impression is that this is what is at the centre of Duffau's criticism: adding a procedure with graver side-effect risks to the "menu" would be professionally irresponsible. It is less clear, however, why he believes this. One reason could be that he finds the riskchance ratio unacceptable as such, linking to the second of the more basic issues above. Forming such an argument will necessitate facing the issue of why the chance of extended life should be discounted - especially so as Duffau argues that if the chance was to "cure" the patient, then the risk would be worth taking. As the particular case discussed regards cancer, it is noteworthy that, apparently, professional colleagues on the pharmacological treatment side seem to be willing to take rather substantial risks of not only suffering and dysfunction, but also of loss of life, to have a chance of quite moderate life extension or (sometimes) mere "progressionfree survival". Is there something about surgery-possibly its backback of historical ethical developments [7]that influences such differences? If so, is such ethical esoterism warranted and, if not, which basic angle on risk assessment enjoys the support of sound ethical theory?
Another argument more clearly indicated by Duffau is the idea that patients may be misled by the introduction of a more risky offer. This concern is dissmissed by Brennum and colleagues as an accusation that they have not told patients the truth. However, the argument may be a worry about patients misunderstanding objectively correct information provided by professionals because of background expectations. This risk probably varies across health care systems, depending on how benign and grim, respectively, the reality of health care and the concerns of professionals are implicitly assumed to be by people in general. The more of idolisation and idealisation, the more serious the risk that patients may misunderstand the offer, no matter how carefully professionals attempt to explain it. However, this holds with equal force for the original offer - e.g., the fact that it provides a lesser than maximal chance of extended survival may not be fully appreciated. The risk of patient misunderstanding is a global hazard in need of attention no matter how the menu of possible treatments is composed.

Brennum and colleagues primarily press reasons of patient autonomy in favour of allowing patients to decide which of the two surgical options to go for, and they hint that Duffau's criticism is based on a lesser willingness to cherish this value. Their argument is in the spirit of what has become known as shared decision making and person centredness - implying a value of including patients in clinical decisions and allowing them to influence what treatments are considered. It is unclear what values are in fact promoted by such changes, however. Autonomy is not automatically among them, and having patients decide raises the question of whether or not they are supported to manage the responsibility implied [8], leading back to one of Duffau's worries. More basically, to get this type of patient involvement off the ground, one first has to decide the realm of available alternatives - excluding what is professionally irresponsible from "the menu" [9]. It is not clear to me what the argument of Brennum and colleagues for adding the expanded option is, however - it cannot be that patients may prefer it, as mere patient preference is no reason to view an offer as professionally responsible. This, then, stands out as the perhaps most likely basic source of disagreement between Brennum's team and Duffau: they hold differing views on whether or not it is professionally responsible to offer a procedure with a more pronounced side-effect profile in light of an increased chance of extending life some more. This disagreement may depend on a cluster of reasons linking back to basic views on what makes life valuable, what makes risks ethically acceptable and assumptions of to what extent patients are prepared to handle the responsibility of making a decision. Possibly an ethics esoterism having developed in the field of surgery may be a factor unwittingly influencing the situation, as well. The disagreement would not seem to be about autonomy. Brennum's and colleagues' claim to the contrary holds only to the extent that Duffau agrees to the 
expanded offer being within the realms of professional responsibility. It seems to me that he does not, however, so my diagnosis is that this issue is the heart of the matter.

Let me close by offering a way to move this issue further on, therefore, employing the classic philosophical method of a thought experiment. Suppose that the situation had been the reverse: the established treatment was the more radical surgery, and someone suggested a more moderate one to become an option with the argument that some patients might prefer a shorter life with a better chance of preserved function. Would that suggestion be within the realm of professional responsibility? Assume that some argue against it, claiming that patients may be misled to believe the chance of extended survival being the same, or that imposing the risk of shortening a patient's life cannot be justified with reference to preserved function. If one agrees with either of these sides, the idea of adding the procedure suggested by Brennum and colleagues would gain support in virtue of pure coherence. Only the view that the new addition has to completely replace the established procedure would seem to support Duffau's view on the issue at hand.

Conflicts of interest None.

\section{References}

1. Brennum J, Maier CM, Almdal K, Engelmann CM, Gjerris M (2015) Primo non nocere or maximum survival in grade 2 gliomas? A medical ethical question. Acta Neurochir (Wien) 157:155-164

2. Duffau H (2015) Preserving quality of life is not incompatible with increasing overall survival in diffuse low-grade glioma patients. Acta Neurochir (Wien) 157:165-167

3. Brennum J, Maier CM, Almdal K, Engelmann CM, Gjerris M (2015) What do we do when attenuation of cerebral function goes hand in hand with maximally effective surgery? Acta Neurochir (Wien). doi: 10.1007/s00701-015-2364-1

4. Brülde B (2007) Happiness and the good life. Introduction and conceptual framework. J Happiness Stud 8:1-14

5. Munthe C (2015) Precautionary principle. Encyclopedia of global bioethics. Dordrecht \& London: Springer, in press

6. Malmqvist E, Juth N, Lynøe N, Helgesson G (2011) Early stopping of clinical trials: charting the ethical terrain. Kennedy Inst Ethics J 21:5178

7. Namm JP, Siegler M, Brander C, Kim TY, Lowe C, Angelos P (2014) History and evolution of surgical ethics: John Gregory to the twentyfirst century. World J Surg 38:1568-1573

8. Munthe C, Sandman L, Cutas D (2012) Person centred care and shared decision making: Implications for ethics, public health and research. Health Care Anal 20:231-249

9. Sandman L, Munthe C (2010) Shared decision making, paternalism and patient choice. Health Care Anal 18:60-84 